\title{
O PROTAGONISMO DAS MULHERES NOS MOVIMENTOS POLÍTICOS PARA A REDEMOCRATIZAÇÃO BRASILEIRA
}

\author{
Isabelle Maria Campos Vasconcelos Chehab ${ }^{1}$
}

\section{Resumo:}

A despeito de sua subalternização histórica, a presença de mulheres nos movimentos de resistência à ditadura civil-militar; pela anistia política de presos e exilados; junto às comissões de familiares de mortos e desaparecidos; e como participantes ativas nos debates e proposições da Assembleia Nacional Constituinte foi elemento essencial para o estabelecimento dos alicerces em prol da redemocratização brasileira. O presente trabalho assume como objetivo central lançar luz, por intermédio de pesquisa bibliográfica interdisciplinar e documental, sobre a magnitude e os efeitos - normativos e institucionais do protagonismo das mulheres nos movimentos políticos pela/para a redemocratização brasileira.

Palavras-chave: Mulheres; Movimentos políticos; Resistência; Redemocratização; Brasil.

\section{THE WOMEN'S PROTAGONISM IN POLITICAL MOVEMENTS FOR BRAZILIAN REDEMOCRATIZATION}

\begin{abstract}
:
Despite their historical subordination, the presence of women in the resistance movements against the civil-military dictatorship; for the political amnesty of prisoners and exiles; with the committees of family members of the dead and missing; and as active participants in the debates and propositions of the National Constitution Assembly, it was an essential element in establishing the foundations for Brazilian redemocratization. This work has the main objective to shed light, through interdisciplinary and documentary bibliographical research, on the magnitude and the effects - normative and institutional - of the protagonism of women in the political movements for Brazilian redemocratization.
\end{abstract}

Keywords: Women; Political movements; Resistance; Redemocratization; Brazil.

\section{INTRODUÇÃO}

Nos intitulados grandes ou pequenos movimentos históricos brasileiros, a despeito da sua subalternização, quando não completa - e deliberada - invisibilidade, as mulheres sempre estiveram presentes. Para sanar qualquer dúvida, basta rememorarmos a participação das

\footnotetext{
${ }^{1}$ Pós-doutoranda e Professora do Programa de Pós-Graduação em Direito Agrário da Universidade Federal de Goiás (PPGDA/UFG). Bolsista PNPD/CAPES. Doutora e Mestra em Direito Constitucional pela Universidade de Fortaleza (UNIFOR). Membro e Coordenadora do Núcleo de Pesquisa em Gênero da Comissão da Mulher Advogada da Ordem dos Advogados do Brasil - Seccional Goiás (CMA/OAB-GO). Advogada. E-mail: ivchehab@gmail.com.
} 
mulheres nos movimentos abolicionistas (Maria Tomásia Figueira Lima, Augusta Generoso Estrella, Maria Amélia de Queiroz e Inês Sabino), nos movimentos pela independência do Brasil (Maria Felipa, Maria Quitéria e Joana Angélica), na inconfidência mineira (Bárbara Heliodora e Hipólita Jacinta Teixeira de Melo), na literatura nacional (Maria Firmina dos Reis, Rachel de Queiroz, Carolina Maria de Jesus e Lygia Fagundes Telles) e nos movimentos sufragistas (Leolinda de Figueiredo Daltro, Gilka Machado, Maria Lacerda de Moura e Bertha Lutz).

Especificamente, no contexto político, a realidade não se apresenta de modo diverso. As mulheres também estiveram presentes nas trincheiras com - e para - a democracia. Consubstanciando um espaço - progressivo - de protagonismo, foram resistência por inúmeras vezes. No curso da ditadura do Estado Novo (1937-1946); em face da ditadura civilmilitar (1964-1985); pelos movimentos de anistia política (1975-1979); e durante a frente parlamentar feminina da Assembleia Nacional Constituinte (1987-1988).

Observa-se, portanto, que as mulheres, historicamente, são partes relevantes dos movimentos políticos que - direta ou indiretamente - contribuíram para a redemocratização brasileira. Sua potência, importância e pluralidade, entretanto, têm sido invisibilizadas no curso da história nacional, razão pela qual se faz tão necessário trazer à luz e debater os seus predicados, desafios e perspectivas, não apenas por uma questão de razoabilidade acadêmica, mas, sobretudo, para auxiliar no estabelecimento de parâmetros - de justiça e equidade - e possibilidades - de inclusão e pluralidade dos mais diversos setores e pautas - aptos a refletir sobre a urdidura de uma democracia de alta densidade no Brasil, que não pode ser implementada sem que haja o devido reconhecimento e a plena participação das mulheres.

Nesses termos, o presente trabalho assume por objetivo central trazer à luz a magnitude e os efeitos - normativos e institucionais - do protagonismo das mulheres nos movimentos políticos pela/para a redemocratização brasileira.

No que tange à metodologia, aclara-se que esta pesquisa é dotada de caráter bibliográfico interdisciplinar, à medida que se permeou o Direito, a Ciência Política, a Sociologia e a História. Também, registra-se o seu cunho documental, em razão da indicação de diversas normas nacionais. De igual modo, deve ser entendida como pesquisa aplicada, considerando o seu intuito de colaborar, por meio dos dados aqui reunidos, para a construção de uma sociedade mais democrática, inclusiva e plural, sobretudo, que considere e reconheça 
o papel das mulheres na sua estruturação. Ademais, trata-se de ensaio eminentemente qualitativo, dada a sua perspectiva de buscar compreender o contexto do objeto investigado, consoante será adiante explicitado.

\section{AS MULHERES NOS MOVIMENTOS DE RESISTÊNCIA À DITADURA CIVIL- MILITAR}

A ditadura civil-militar instaurada no Brasil, a partir de um golpe de Estado deflagrado aos 31 de março de 1964, usou de extrema crueldade para com os seus resistentes. Diferentemente do propalado por alguns dos seus defensores, a ditadura civil-militar nada se assemelha com o trocadilho "ditabranda". Consoante provas documentais, periciais e testemunhais examinadas pela Comissão Nacional da Verdade $(\mathrm{CNV})^{2}$, órgão criado no âmbito da Casa Civil da Presidência da República, por intermédio da Lei n. 12.528, de 18 de novembro de 2011, com a finalidade de efetivar o direito à memória e à verdade histórica e promover a reconciliação nacional, o estado de exceção ditatorial brasileiro albergou 377 agentes públicos vinculados - direta ou indiretamente - a graves violações de direitos humanos $^{3}$ em face de resistentes do regime, além de 229 instituições e locais associados a graves violações de direitos humanos, relacionados entre unidades militares e policiais e centros clandestinos (BRASIL, 2014, p. 830-831). Objetivamente, somente nos primeiros meses posteriores ao golpe de 1964, pelo menos, 100.000 pessoas foram torturadas por agentes da repressão e, durante toda a sua vigência, 434 pessoas já foram reconhecidas oficialmente entre mortas e desaparecidas políticas - podendo tal número ser

\footnotetext{
${ }^{2}$ É importante registrar que a CNV, "durante o seu mandato legal, valeu-se do acúmulo documental já sistematizado pelo Arquivo Nacional (AN), pela Comissão Especial sobre Mortos e Desaparecidos (CEMDP) e pela Comissão de Anistia (CA) (BRASIL, 2014, p. 58-60). Em adição, colheu 1.116 depoimentos de vítimas e agentes da repressão, sendo 483 em audiências públicas e 633 em caráter reservado (BRASIL, 2014, p. 55), conjugados aos relatórios e às informações amealhados pelas Comissões estaduais e setoriais. (BRASIL, 2014, p. 55). Para além de seus grupos de trabalho especializados, a CNV estruturou equipes internas de comunicação; ouvidoria ; diligências e perícias." (CHEHAB, 2015, p. 101)

${ }^{3}$ Consoante Relatório da CNV, "A expressão 'graves violações de direitos humanos' é utilizada para designar violação a direitos considerados inderrogáveis, como o direito à vida e à integridade pessoal, não sendo passíveis de suspensão mesmo em situações excepcionais - a guerra, o estado de emergência, o estado de perigo etc. Desde os primeiros estudos na década de 1990, o conceito tem se ampliado para indicar a transgressão a normas imperativas do direito internacional, como aquelas referentes à proibição do genocídio, dos crimes de guerra e dos crimes contra a humanidade. Diante da inexistência de um rol estritamente definido de graves violações de direitos humanos em tratados ou em legislação interna, tem cabido prioritariamente aos tribunais internacionais de direitos humanos a identificação de tais violações. Como nota geral, pode-se dizer que hoje constituem graves violações de direitos humanos: detenções ilegais e arbitrárias; tortura e outros tratamentos ou penas cruéis, desumanos ou degradantes; execuções sumárias, arbitrárias e extrajudiciais; e desaparecimentos forçados, contemplados, aqui, os casos de ocultação de cadáveres". (BRASIL, 2014, p. 37-38, grifou-se).
} 
significativamente ampliado, se considerados, por exemplo, os massacres perpetrados contra comunidades indígenas e camponesas ${ }^{4}$, até hoje, ainda não completamente desvendados.

No que concerne especificamente às mulheres, a ditadura civil-militar obedeceu um verdadeiro rito de horrores e atrocidades. Primeiramente, em face daquelas que eram consideradas como inimigas diretas do regime, ou seja, aquelas mulheres que faziam parte dos movimentos de resistência à ditadura civil-militar no campo da política, das artes e/ou da educação, as quais, se fossem presas, via de regra, eram submetidas, consoante relatos das próprias sobreviventes e/ou de agentes da repressão, a sistemáticas humilhações, torturas, violências sexuais, desaparecimentos forçados e/ou execuções sumárias, o que se aplicava, inclusive, para grávidas e puérperas. Nesse grupo, estão, pelo menos, 51 mulheres, o que corresponde a $12 \%$ dos mortos e desaparecidos pela ditadura civil-militar. Na sua maioria, portanto, em quase $85 \%$ desses casos, tratavam-se de mulheres jovens de até 30 anos, originárias tanto do meio urbano quanto no meio rural ${ }^{5}$.

Somados a esses dados numéricos, é importante esclarecer que, consoante o Relatório da CNV, o modus operandi ali utilizado para cometer graves violações de direitos humanos contra as mulheres era dotado de particularidades, voltadas, no mais das vezes, para a destruição não apenas dos seus corpos, como também do seu universo feminino e, em alguns casos, do seu próprio direito de resguardo à concepção e à maternidade. Igualmente, é razoável ponderar que, embora as mulheres participassem ativamente de movimentos políticos de resistência, ocupando, em alguns casos, a linha de frente das atividades/operações ali promovidas, elas dificilmente eram consideradas para exercer atividades de liderança nas suas organizações. Deste modo, se eram miradas e, muitas vezes, minadas pelas forças da repressão, em razão da sua condição feminina; no seio das suas organizações, comumente, elas também eram alvos de preconceitos pelos seus dirigentes, que subestimavam a sua capacidade - física e intelectual - e pouco compartilhavam das suas políticas estratégicas. (TELES, 1993, p. 64-65)

\footnotetext{
${ }^{4}$ Estima-se que, ao longo da sua existência de 21 anos, a ditadura civil-militar, por intermédio de seus agentes, tenha atingindo algo em torno de 1.196 camponeses, entre mortos e/ou desaparecidos. (BRASIL, 2014, p. 25).

${ }^{5}$ As resistências rurais são pouco comentadas, mas não somente elas existiram durante a ditadura civil-militar, como foram elementos cruciais para o enfrentamento das forças repressivas. As Ligas Camponesas, por exemplo, foram um dos movimentos mais atuantes no âmbito rural brasileiro. Com duração breve, entre 1955 e 1964, alcançou em torno de 80 mil filiados. (MORAIS, 2006, p. 66-67). Desempenharam um papel importante na primeira resistência ao golpe de 1964, quando foi violentamente reprimida.
} 
Nesse contexto, podem ser citados alguns casos emblemáticos, a exemplo de Crimeia Schmidt de Almeida, militante do Partido Comunista do Brasil (PC do B) e uma das sobreviventes da Guerrilha do Araguaia, que foi sequestrada, presa e brutalmente torturada quando estava grávida de seis meses, consoante o relato abaixo:

[...] Era feito com acompanhamento médico, médico ou, pelo menos, que se dizia médico. Disse o tipo de tortura que eles poderiam fazer, recomendava que não espancassem a barriga e não dessem choques elétricos na vagina, na boca, nos órgãos mais internos, né? Ouvidos... E depois que esse médico, sei lá se é médico, o que que é isso, falou isso, ficou nessa sala. Então, eu não fui pendurada no pau de arara e eles priorizaram muito a tortura psicológica. [...] Meu filho tinha soluços na barriga. Meu filho tem soluços até hoje [...] Qualquer tensão, ela se manifesta com soluços. (BRASIL, 2014, p. 411-412)

Infelizmente, Maria Amélia de Almeida Telles, irmã de Criméia, também faz parte do rol de casos emblemáticos entre as mulheres que foram submetidas a graves violações de direitos humanos pela ditadura civil-militar. Amelinha era uma militante histórica do Partido Comunista do Brasil (PC do B), o que motivou a sua prisão no ano de 1972, juntamente com o seu marido, César Augusto Telles, e seus dois filhos, ainda crianças, Janaína e Edson, então com 5 e 4 anos de idade, respectivamente, os quais restaram conhecidos como um dos mais novos presos da ditadura, uma vez que, nesta tenra idade, foram sequestrados pelos agentes da repressão e obrigados a acompanhar a sessão de tortura dos seus próprios pais na Operação Bandeirantes (OBAN), em São Paulo - SP. Em 2006, a família Almeida Telles, o que inclui Criméia, ajuizou uma ação declaratória em face de Carlos Alberto Brilhante Ustra, por meio da qual se requereu e, ao final, foi concedida: “(...) sentença que declarou o coronel Ustra torturador quando era comandante do DOI-CODI/SP, ao reconhecer sua responsabilidade pelo uso de violência contra a família Almeida Teles. Ao definir o DOI-CODI como 'casa dos horrores', tomou decisão inédita e histórica no Brasil” (TELES, 2010, p.295-296), embora que objeto de diversos recursos aos tribunais superiores. ${ }^{6}$

\footnotetext{
${ }^{6}$ Tal decisão foi submetida à seara recursal, por meio da Apelação no 2013/0416218-0, proposta por Brilhante Ustra e denegada pelo Tribunal de Justiça do Estado de São Paulo. Na sequência, em 7 de janeiro de 2014, foi oposto um Recurso Especial n ${ }^{\circ}$ 1434498/SP pela defesa de Brilhante Ustra perante o Superior Tribunal de Justiça (STJ), que lhe negou provimento, em 5 de fevereiro de 2015, por meio dos votos dos Ministros de sua $3^{\text {a }}$. Turma Paulo de Tarso Sanseverino, Ricardo Villas Bôas Cueva e Marco Aurélio Bellizze, tendo sido vencida a Ministra Relatora Nancy Andrighi e o Ministro João Otávio de Noronha (BRASIL. STJ, 2015, ONLINE). Posteriormente, foram apresentados Embargos de declaração, os quais foram rejeitados, em 07 de abril de 2015, pela mesma $3^{\text {a }}$. Turma do STJ, inclusive, com aplicação de multa em desfavor de Carlos Alberto Brilhante Ustra, quem, ingressou com um Recurso Extraordinário, novamente, não admitido, agora, por decisão monocrática da lavra da Ministra Laurita Vaz, na data de 18 de junho de 2015. Atualmente, os autos do recurso foram remetidos, na data
} 
Por semelhante modo, merece registro o ocorrido com Inês Etienne Romeu, historiadora, que na época contava com 28 anos de idade e era militante da Vanguarda Popular Revolucionária (VPR) e da Organização Revolucionária Marxista-Política Operária (POLOP). Inês foi a única sobrevivente de um centro clandestino equipado para operacionalizar graves violações de direitos humanos contra resistentes da ditadura civilmilitar, conhecido como Casa da Morte, situado em Petrópolis, na região serrana do estado do Rio de Janeiro, “(...) criado, organizado e mantido pelo Centro de Informações do Exército (CIE). A casa situava-se na rua Arthur Barbosa, no 50 (antigo 668), no bairro de Caxambu, e foi cedida em 1971 pelo proprietário à época, Mario Lodders, ao ex-comandante da companhia aérea Panair e ex-interventor de Petrópolis, Fernando Aires da Mota.” Lá, Etienne Romeu “(...) esteve cem dias em cárcere privado, onde foi submetida a coações e sevícias de ordem física, psicológica e moral” (ARQUIDIOCESE DE SÃO PAULO, 2009, p. 239). Como se não bastasse, mesmo após deixar a Casa da Morte, foi alvo de vigilância constante pelos agentes da repressão, os quais lhe faziam, dentre outras, as seguintes ameaças: "Meus carrascos afirmaram que "me suicidariam" na prisão, caso eu revelasse os fatos que ouvi, vi e que me contaram durante os três meses de minha prisão, pois reconhecem que "sei demais". Querem que eu morra "naturalmente", sem que sejam responsabilizados pela morte que me impingirem.” (BRASIL, 2014, p. 377) Por diversas vezes, e perante a inúmeras instâncias, até o seu óbito, em 2015, Inês Etienne denunciou as atrocidades contra ela cometidas na Casa Morte. No último dia 19 de agosto do corrente, o Tribunal Regional Federal da $2^{\mathrm{a}}$. Região (TRF- 2a . Região), reformando decisão absolutória de primeira instância, decidiu “(...) aceitar a denúncia dela de sequestro e estupro contra o sargento reformado Antônio Waneir Pinheiro de Lima, conhecido como Camarão. Trata-se do primeiro processo criminal de estupro aberto contra militares por crimes cometidos durante a ditadura." (OLIVEIRA, 2019, ONLINE)

Por intermédio desses três casos emblemáticos, verifica-se que todas as mulheres citadas participavam ativamente de movimentos de resistência à ditadura civil-militar instaurada no Brasil, destarte, as graves violações ali perpetradas, diga-se de passagem: todas capitaneadas e executadas por homens - não eram apenas dirigidas ao seu caráter pessoal, mas tinham o condão de imprimir danos - morais e simbólicos - às próprias organizações que elas, de algum modo, representavam. Por outro lado, é importante observar que as graves

de 6 de julho de 2015, em caráter recursal, para o STF, onde recebeu o número de controle 193970(123). (BRASIL. STJ, 2015, ONLINE). 
violações de direitos humanos praticadas contra as mulheres eram dotadas de especificidades em razão do gênero, operando para deslegitimar, subalternizar e afligir sua condição feminina, inclusive, com requintes de barbárie, para os casos de grávidas e puérperas. Ainda, deve ser ressaltado que, a despeito de todas as graves violações de direitos humanos a que foram submetidas no curso da ditadura, as mulheres aqui declinadas não se curvaram perante a dor e prosseguiram suas lutas por justiça e verdade, nas instâncias próprias, o que ensejou para si e para tantas outras em circunstâncias paradigmáticas, um legado de resistência à matriz do autoritarismo, da exceção e do patriarcado.

\title{
2. AS MULHERES NOS MOVIMENTOS PELA ANISTIA POLÍTICA E NA COMISSÃO DE FAMILIARES DE MORTOS E DESAPARECIDOS POLÍTICOS (CFMDP)
}

Consoante Del Porto (2009, p. 61), há registros que comprovam que as reivindicações por anistia se constituíram em um processo progressivo de lutas e embates, iniciado, mesmo que timidamente, já no ano que sucedeu o golpe civil-militar, passando a ganhar alguma consistência com a formação da Frente Ampla no Congresso Nacional por redemocratização, no ano de 1967. Na sequência, em 1968, tal discussão ascendeu a novos patamares ao ser apresentado "[...] o primeiro projeto de anistia, que anistiaria todos os punidos em decorrência do envolvimento nas manifestações em razão da morte do estudante Edson Luís." (DEL PORTO, 2009, p. 62).

Com o arrefecimento da luta $\operatorname{armada}^{7}$, uma diversidade de movimentos e críticos da ditadura começou a se aglutinar em torno de uma oposição legalizada, então representada pelo MDB (Movimento Democrático Brasileiro), que, já nas eleições legislativas de 1974, alcançaram uma vitória significativa contra a ditadura e os seus representantes, a saber:

\begin{abstract}
O MDB teve mais de $70 \%$ dos votos nos grandes centros, e sua bancada de deputados pulou de 87 para 160 deputados. É verdade que a Arena fora vencedora no cômputo geral, registrando 11,9 milhões de votos contra 11 milhões do MDB (40,9\% contra $37,8 \%$, e $21,3 \%$ de votos brancos e nulos), e que o MDB permanecia minoritário no Congresso Nacional (203×161 deputados). Entretanto a oposição já tinha força para convocar ministros, para formar Comissões Parlamentares de Inquérito (CPIs) e, o que era mais importante, barrar, se fosse o caso, eventuais reformas constitucionais, que exigiam dois terços dos votos. (REIS, 2014, p. 107).
\end{abstract}

\footnotetext{
${ }^{7}$ Embora no início da década de 70 a luta armada já estivesse demonstrando sinais de enfraquecimento, dados os desaparecimentos, mortes e prisões de muitos dos seus militantes durante a guerrilha urbana, foi, sobretudo, a partir da segunda metade da década de 70, com especial destaque para a dizimação perpetrada pelas Forças Armadas contra a Guerrilha do Araguaia (1972-1974), que a esquerda armada perdeu sua força. Em decorrência desses fatos, os movimentos e militantes da esquerda foram instados a se organizar em torno da oposição consentida pela ditadura civil-militar, que se fazia representar pelo MDB.
} 
Foi, entretanto, com a criação do Movimento Feminino pela Anistia (MFPA), em 1975, por Therezinha de Godoy Zerbini, advogada, ex-presa política e esposa de um general cassado, que o assunto da anistia ganhou uma visibilidade mais ampla. Tal Movimento assumiu como objetivo central mobilizar as mulheres em prol da anistia política, arrecadando, apenas no seu primeiro ano, cerca de 16 mil assinaturas para o Manifesto da Mulher Brasileira pela Anistia. (DEL PORTO, 2009, p. 61).

O MFPA destacou-se, também, por ter sido o primeiro movimento, que protagonizou, durante o período de distensão política, uma luta sistemática pela anistia, ousando enfrentar, mesmo que tangencialmente, as estruturas políticas e repressivas da ditadura (SANTA CRUZ, 2009, p. 115), colaborando, assim, para a disseminação da ideia de anistia por todo o território nacional. ${ }^{8}$

Seu intento era, pois, implementar a anistia pela paz, a saber: "As mulheres do Movimento Feminino Pela Anistia (MFPA) escolheram a paz como tema principal para ligálas diretamente à questão da anistia, já que, na concepção delas, anistia significava paz, pois o país estava dividido (...)" (SOUZA, 2012, p.28).

Ocorre que a bandeira defendida pelo MFPA de uma anistia “"...] pensada como perdão e esquecimento" (ARANTES, 2009, p. 84) não era um consenso entre os seus militantes, especialmente por aqueles que tinham vínculos afetivos ou políticos com os que estavam presos, o que findou por dispersar ideologicamente parte de seus apoiadores, senão vejamos:

\begin{abstract}
[...] era um movimento voltado particularmente para o exílio e para aqueles que, de uma forma ou de outra, tivessem sido expulsos das Forças Armadas ou dos seus postos de trabalho. Tratava-se de reintegrar centenas de cidadãos ilustres ao processo político nacional. Havia por parte desse movimento um claro constrangimento ao se referir aos presos políticos que, em sua grande maioria, haviam sido condenados pela Lei de Segurança Nacional e enquadrados nos artigos relativos a ações armadas contra a ditadura. (SOUSA, 2011, p. 200).
\end{abstract}

Para contemplar aqueles que haviam sido excluídos dos debates firmados pelo MFPA, foram articulados, a partir de 1977, e efetivamente criados, em 1978, os Comitês Brasileiros pela Anistia (CBAs), espaços políticos de resistência à ditadura civil-militar, disseminados por todo o país, ${ }^{9}$ com o propósito de promover uma anistia ampla, geral e irrestrita. Assim,

${ }^{8}$ De acordo com André Pinheiro de Souza (2012, p. 31): "No Ceará, as articulações e as reuniões para a criação do MFPA aconteciam em fins do ano de 1975, porém, regulamentado, apresentado ao público e à sociedade de uma maneira geral por meio da Conferência de lançamento, em dia 15 de março de 1976 com a presença da Dona Theresinha (sic) Zerbini, presidente nacional do Movimento Feminino pela Anistia (MFPA)."

${ }^{9}$ Nesse sentido, expõe André Pinheiro de Souza: "No Ceará, em meio a esse cenário de efervescências, de debates e de diálogos, foi criado, no dia 10 de março de 1979, o Comitê Brasileiro Pela Anistia, secção Ceará (CBA-CE). 
Os Comitês Brasileiros pela Anistia (CBAs) surgem como uma organização independente, reunindo homens e mulheres dispostos a levar à frente um programa político mínimo e de ação que ia além do esquecimento e exigia a libertação imediata de todos os presos políticos; a volta de todos os exilados, banidos e cassados; a reintegração política, social e profissional dos funcionários públicos ou privados demitidos por motivos políticos em conseqüência dos efeitos dos Atos de Exceção; o fím radical e absoluto da tortura; a revogação da Lei de Segurança Nacional; o desmantelamento do aparato repressivo; o esclarecimento das mortes e dos desaparecimentos por motivação política; a denúncia sistemática da tortura e dos casos de mutilação; o julgamento e a punição dos responsáveis. (ARANTES, 2009, p. 84).

Como embrião dessas duas iniciativas, quais sejam MFPA e CBA, e em resposta à edição da Lei n. 6.683, de 28 de agosto de 1979, conhecida como Lei de Anistia, foi criada a Comissão de Familiares de Mortos e Desaparecidos Políticos (CFMDP), constituída, principalmente por familiares, frise-se, sobretudo, mulheres, que se sentiram desamparados pela norma aprovada no Congresso Nacional. Tal Lei de anistia, ou autoanistia, era restritiva para os que cometeram atos de resistência contra o regime ditatorial, especificamente no que tange aos chamados "crimes de sangue", e, por outro lado, demasiadamente parcimoniosa para com os agentes da repressão. Na verdade, a redação do $\S 1^{\circ}$., do art. $1^{\circ}$. da Lei $n^{\circ}$. 6.683/79 foi propositalmente genérica, uma vez que foram ali constituídos como crimes conexos todos aqueles de algum modo relacionados com crimes políticos ou praticados por motivação política. Destarte, ao não especificar quais seriam os crimes conexos, o legislador oportunizou uma interpretação sobremodo extensiva aos mais diversos crimes cometidos por agentes da ditadura, frise-se: sem qualquer vinculação direta com questões políticas ou assemelhadas, entre os quais, podem ser citados: estupros, seqüestros, homicídios e latrocínios.

Por via consequente, todos os agentes da repressão que praticaram crimes dos mais variados matizes, se instados judicialmente, poderiam alegar que os crimes outrora cometidos tinham natureza política - ou motivação política - para serem legalmente escusados dos seus atos, recebendo um perdão político prévio, que lhe garante a impunibilidade - tudo em razão da interpretação ultraextensiva providenciada pela Lei de Anistia.

Diante desse contexto, dezenas de familiares se reuniram em torno da CFMDP, para refletir, discutir e articular medidas políticas, administrativas e judiciais que pudessem, de

O ano de 1979 estava sendo decisivo no tocante a questão da anistia política, tanto em âmbito nacional, quanto local. A criação do CBA-CE teve grande importância, pois veio como um reforço na melhoria das condições carcerárias que estavam em progressiva deterioração. O CBA-CE foi fruto do grupo de mulheres, que desde 1975, criaram, em nosso Estado, o núcleo do Movimento Feminino Pela Anistia e, consequentemente, plantaram as primeiras sementes dessa luta, que naquele momento, dava um vigoroso passo." 
algum modo, enfrentar os efeitos nefastos estabelecidos pela Lei de Anistia para obstaculizar qualquer espécie de responsabilização em face dos agentes da repressão pelas graves violações de direitos humanos cometidas durante a ditadura civil-militar. Tais esforços redundaram na coordenação de atividades pontuais, como a realização de atos de visibilidade e denúncia protagonizados pelos familiares de mortos e desaparecidos políticos; expedição de familiares ao local da Guerrilha do Araguaia; organização do Tribunal Tiradentes e participação nas atividades da Comissão Especial de Investigação das Ossadas de Perus (CEIOP), assim como na concretização de ações sistemáticas, como a reconstituição de listas de mortos e desaparecidos pela ditadura civil-militar; realização de atos de memória em prol de presos e desaparecidos políticos; e participação em encontros e congressos com familiares de mortos e desaparecidos do Cone Sul. (GALLO, 2012, p. 337-338)

A luta constante dos familiares, embora que longe de alcançar os objetivos a que propõem e sem o reconhecimento governamental que lhe é devido, rendeu alguns frutos normativos e institucionais, dentre os quais, merecem ênfase: a criação da Comissão Especial sobre Mortos e Desaparecidos Políticos (CEMDP), por meio da Lei $\mathrm{n}^{\circ}$ 9.140, de 4 de dezembro de 1995, que se revestiu de grande relevância histórica, tendo em vista que representou o primeiro esforço institucional - e perene - do Estado brasileiro de promover a busca e o reconhecimento dos mortos e desaparecidos políticos, e, assim, concretizar uma dos mais milenares direitos do ser humano, qual seja prantear e enterrar os seus mortos, pertinente à dimensão da verdade e da memória na justiça transicional. (BRASIL, 1995, ONLINE); e a instituição da Comissão de Anistia, por meio da Medida Provisória no 2.151-3, de 24 de agosto de 2002, posteriormente, convertida na Lei $\mathrm{n}^{\mathbf{0}} 10.559 / 2002$, com a finalidade de examinar os requerimentos fundamentados neste diploma legal e assessorar o respectivo Ministro de Estado em suas decisões, anteriormente no âmbito do Ministério da Justiça, e atualmente no bojo do Ministério da Mulher, da Família e dos Direitos Humanos.

Observa-se, portanto, que a anistia defendida pelos CBAs era significativamente distinta da pleiteada pelo MFPA, sobretudo, porque pautada, entre outras diretrizes, na responsabilização de todos aqueles que colaboraram para o cometimento de graves violações de direitos humanos; na reestruturação política e administrativa do Estado e na revogação do arcabouço jurídico autoritário. Destarte, verifica-se que, embora diametralmente opostas em suas concepções de fundo sobre a anistia política, o MFPA e os CBAs foram, juntos, deveras relevantes para a disseminação dos debates em torno da matéria no seio social. Mais: serviram 
como pontes para que muitas mulheres atingidas, direta ou indiretamente, pelas graves violações de direitos humanos praticadas pela ditadura, sobretudo, em decorrência das mortes e desaparecimentos dos seus familiares, pudessem se engajar, participar e protagonizar movimentos de resistência democrática juntamente com outras pessoas em situações que lhes eram assemelhadas, com destaque para criação e a implementação de atividades desempenhadas pela Comissão de Familiares de Mortos e Desaparecidos Políticos (CFMDP), composta e coordenada majoritariamente por mulheres.

\section{OS MOVIMENTOS E AS FRENTES PARLAMENTARES FORMADAS POR MULHERES NA ASSEMBLEIA NACIONAL CONSTITUINTE (1987-1988)}

Dando sequência aos movimentos protagonizados por mulheres na resistência à ditadura civil-militar, para a aprovação da Lei de Anistia e para o reconhecimento e buscas de mortos e desaparecidos políticos, tem-se a organização de movimentos - setoriais e regionais - e frentes parlamentares, inclusive uma exclusivamente feminina, formados para debater e propor direitos para as mulheres no contexto da Assembleia Nacional Constituinte (19871988). (CISNE, 2014, p. 27)

Nesses termos, as mulheres, embora que tendo ali um número limitado de constituintes, apenas, 26, conquistaram um espaço significativo nas grandes discussões políticas nacionais.(SOUZA,2008,p.3) Num movimento histórico, as representantes femininas da Assembleia Constituinte conseguiram se aliar a diversos segmentos e movimentos da sociedade civil, assim como a entidades de classe e organismos internacionais para dar visibilidade, firmar posições e garantir a inclusão de diversas demandas da agenda feminista no texto da Constituição da República Federativa de 1998, dentre as quais, merecem ser listadas: art. $5^{\circ}$, inciso I, que dispõe sobre a igualdade, em direitos e obrigações, de homens e mulheres; art. $7^{\circ}$, inciso $\mathrm{XX}$, diz respeito à proteção do mercado de trabalho da mulher, mediante incentivos específicos, nos termos da lei; art. $226, \S 5^{\circ}$, que trata da igualdade de direitos e deveres referentes à sociedade conjugal; art. 226, $\S 7^{\circ}$, concernente ao planejamento familiar como livre decisão do casal; art. 226, $\S 8^{\circ}$, referente à assistência que o Estado deve prestar à família na pessoa de cada um dos que a integram, criando mecanismos para coibir a violência no âmbito de suas relações.|(CHEHAB, 2018, p. 80)

Durante a década de 90, tal texto constitucional, debatido e urdido amplamente por mulheres, deu azo para que inúmeras das matérias ali tratadas pudessem ser editadas e/ou 
regulamentadas por meio de normas específicas, a exemplo do Estatuto da Criança e do Adolescente (Lei n. 8.069/90) e da Lei Orgânica de Assistência Social (Lei n. 8.742/93) Por semelhante modo, a Constituição Federal de 1988 trouxe as principais bases necessárias, como a determinação da igualdade entre homens e mulheres, a explicitação do princípio da dignidade da pessoa humana e a atribuição de responsabilidade ao Estado na criação de mecanismos preventivos à violência no âmbito doméstico, para a edição, a partir do ano de 2003, durante os governos populares de Luís Inácio Lula da Silva e Dilma Rousseff, das seguintes normas: Estatuto do Idoso (Lei n. 10.741/2003); Lei Maria da Penha (Lei n. 11.340/2006); Lei das Trabalhadoras Domésticas (LC 150/2015); e Lei do Feminicídio (Lei n. 13.104/2015). (BIROLI, 2018, p. 187)

Em sentido de concomitância com o aumento de normativas referentes - direta ou indiretamente - ao direito das mulheres em geral e à sua participação na política, ampliaramse, a partir da redemocratização, o número de espaços e sujeitos informais de participação, a exemplo das marchas populares, coletivos feministas e movimentos sociais, que perfilharam um caminho independente dos lugares e das construções da política tradicional, acolhendo, progressivamente, diferentes vozes, propondo uma agenda plural, e catalisando, ainda, que sem lograr êxito na transformação das estruturas patriarcais, o olhar e as vivências dos costumeiramente subalternizados, sobretudo, de/com/para mulheres.

\section{CONCLUSÃO}

O presente desmistificou a ideia - ainda - corrente concernente à diminuta participação política das mulheres nos movimentos políticos - e históricos - do Brasil, a partir da análise de dados numéricos, registros documentais e fontes bibliográficas interdisciplinares, considerando, para tanto, as atividades políticas implementadas em caráter tradicional, assim como a militância política informal forjada e protagonizada por - e para - mulheres, no interregno temporal entre a instauração da ditadura civil-militar e a redemocratização brasileira.

Igualmente, observou-se, por intermédio de números, relatos pessoais, provas documentais e testemunhais, o relevante papel desempenhado pelas mulheres no bojo dos movimentos de resistência à ditadura civil-militar, a despeito das sistemáticas e graves violações de direitos humanos a que foram submetidas, a exemplo de detenções ilegais e 
arbitrárias; tortura e outros tratamentos ou penas cruéis, desumanos ou degradantes, e estupros, muitas delas, inclusive, diretamente prejudiciais à sua condição feminina e maternal.

Por semelhante modo, verificou-se que a participação das mulheres na construção dos movimentos pela anistia política, tais como o MFPA e os CBAs, foi de suma relevância para espraiar e oxigenar os debates em torno dessa temática por todo o seio social e, por via consequente, abrir novas possibilidades para sua consecução. Conquanto a própria Lei de Anistia não tenha rendido bons frutos aos familiares de presos, mortos e desaparecidos políticos, dada a sua parcimônia quase que irrestrita para com os agentes da repressão, de algum modo, oportunizou às famílias uma aproximação estratégica com novos atores e propostas, via CFMDP, ensejando-lhes, consequentemente, uma profunda reflexão sobre a sua militância, a organização de novas ações e campanhas e a realização de objetivos institucionais e normativos - para o porvir.

Ainda, constatou-se que, embora estivessem presentes vários obstáculos institucionais e numéricos, as mulheres conseguiram estabelecer uma articulação suprapartidária eficaz e apta a incluir, no curso da Assembleia Nacional Constituinte, uma quantidade superior a cem emendas no texto constitucional de 1988, garantindo não apenas à sua fundamentalidade formal, como também à sua instrumentalização normativa e institucional, por intermédio de diversas normas infraconstitucionais e políticas públicas que lhe são decorrentes.

Por derradeiro, concluiu-se que as mulheres foram sujeitos ativos e fundamentais para engrossar as fileiras dos movimentos políticos e urdir meios e instrumentos para a redemocratização brasileira, o que inclui, em sentido cronológico, a resistência à ditadura, os debates em torno da anistia política, a militância na CFMDP e a participação na Assembleia Nacional Constituinte. A grande questão contemporânea, todavia, é encontrar formas, espaços e sujeitos dispostos a avançar nessa pauta e seguir rumo à democracia de alta densidade, a qual deve enfrentar, necessariamente: o tratamento e repúdio ao passado de graves violações a que fomos submetidas durante a ditadura civil-militar; o acolhimento e fomento de novas vozes de meninas e/ou mulheres comprometidas com os direitos humanos, com a agenda feminista e com a democracia; e, principalmente, a transformação das estruturas patriarcais arcaicas brasileiras, ainda tão presentes no nossos cotidiano, que findam por funcionar, infelizmente, como severos óbices ao projeto de democracia progressista, inclusiva e plural que almejamos. 


\section{REFERÊNCIAS}

ARANTES, Maria Auxiliadora de Almeida Cunha. O Comitê Brasileiro pela Anistia de São Paulo (CBA-SP): memória e fragmentos. In: SILVA, Haike R. Kleber da (Org.). A luta pela anistia. São Paulo: UNESP, 2009.p.83-99.

ARQUIDIOCESE DE SÃO PAULO. Brasil Nunca Mais. 38 ed. Rio de Janeiro: Vozes, 2009.

BIROLI, Flávia. Gênero e desigualdades: limites da democracia no Brasil. São Paulo: Boitempo, 2018.

BRASIL. Comissão Nacional da Verdade. Relatório final da CNV. Brasília: CNV, 2014. BRASIL. Constituição (1988). Constituição da República Federativa do Brasil de 1988. Brasília, DF, Senado, 1988. Disponível

em:<http://www.planalto.gov.br/ccivil_03/constituicao/constitui\%C3\%A7ao.htm.>. Acesso em: 3 ago. 2019.

CHEHAB, Isabelle Maria Campos Vasconcelos. Movimentos feministas no Brasil: ciclos históricos, velhos desafios e novas propostas de resistência no contexto da pós-democracia. THEMIS, Fortaleza, v. 16, n.2, p. 71-89, jul/dez, 2018.

Da ditadura civil-militar à justiça de transição no Nordeste brasileiro:

fundamentos, ciclos históricos, lutas e memórias. Fortaleza, UNIFOR, 2015. 235p. Tese

(Doutorado em Direito Constitucional). Programa de Pós-Graduação em Direito

Constitucional, Universidade de Fortaleza, 2015.

CISNE, Mirla. Feminismo e consciência de classe no Brasil. São Paulo: Cortez, 2014.

DEL PORTO, Fabíola Brigante. A luta pela anistia no regime militar brasileiro e a construção dos direitos de cidadania. In: SILVA, HaikeR. Kleber (Org.). A luta pela anistia. São Paulo: UNESP, 2009. p.59-79.

GALLO, Carlos Artur. Do luto à luta: um estudo sobre a Comissão de Familiares de Mortos e Desaparecidos Políticos no Brasil. Anos 90, Porto Alegre, v. 19, n. 35, p. 329-361, jul. 2012. MORAIS, Clodomir Santos de. História das Ligas Camponesas do Brasil - 1969. In: STÉDILE, João Pedro (Org.). História e Natureza das Ligas Camponesas - 1954-1964. A questão Agrária no Brasil. Expressão Popular. São Paulo, 2006.

OLIVEIRA, Joana. Em caso inédito, militar será julgado por estupro de presa política. El País. Disponível em: < https://brasil.elpais.com/brasi1/2019/08/14/politica/1565802126_256909.html> Acesso em: 31 ago. 2019.

PRESOT, Aline. Celebrando a "Revolução": as marchas da família com Deus peela Liberdade e o Golpe de 1964. In: ROLLEMBERG, Denise; QUADRAT, Samantha Viz. (Org.). A construção dos regimes autoritários: legitimidade, consenso e consentimento no século XX. Rio de Janeiro: Civilização Brasileira, 2010. p.71-96.

REIS, Daniel Aarão. Ditadura e democracia no Brasil. Rio de Janeiro: Zahar, 2014.

SANTA CRUZ, Rosalina. Elas se revelam na cena pública e privada: as mulheres na luta pela anistia. In: SILVA, HaikeR. Kleber. A luta pela anistia. São Paulo: UNESP, 2009.p.111-123. SOUSA, Jessie Jane Vieira de. Anistia no Brasil: um processo político em disputa. In: PAYNE, Leigh A. et al. A anistia na era da responsabilização: o Brasil em perspectiva internacional e comparada. Brasília: Ministério da Justiça, 2011.p.188-210.

SOUZA, André Pinheiro de. Do movimento feminino pela anistia (MFPA-CE) ao comitê brasileiro pela anistia (CBA-CE): as motivações e os caminhos percorridos pela anistia política no Ceará (1975 a 1980). Fortaleza, UECE, 2012. 165p. Dissertação (Mestrado em História). Centro de Humanidades, Universidade Estadual do Ceará, 2012. 
SOUZA, Marcius F.B. de. A participação das mulheres na elaboração da Constituição de 1988. Constituição de 1988: O Brasil 20 anos depois. Os Alicerces da Redemocratização. Brasília: Senado Federal, 2008.

TELES, Maria Amélia de Almeida. Breve história do feminismo no Brasil. São Paulo: Brasiliense, 1993.

TELES, Edson Luís de Almeida; SAFATLE, Vladimir (Org.). O que resta da ditadura. São Paulo: Boitempo, 2010. 